\title{
Lipectomy associated to obesity produces greater fat accumulation in the visceral white adipose tissue of female compared to male rats
}

Fábio da Silva Pimenta ${ }^{2}$, Hadnan Tose ${ }^{3}$, Élio Waichert $\mathrm{Jr}^{4}$, Márcia Regina Holanda da Cunha ${ }^{5}$, Fabiana Vasconcelos Campos ${ }^{1}$, Elisardo Corral Vasquez ${ }^{2}$ and Hélder Mauad ${ }^{1 *}$ (i)

\begin{abstract}
Background: Mobility of fat deposited in adipocytes among different fatty territories can play a crucial role in the pathogenesis of obesity-related diseases. Our goal was to investigate which of the remaining fat pads assume the role of accumulating lipids after surgical removal of parietal WAT (lipectomy; LIPEC) in rats of both sexes displaying MSG-induced obesity.

Methods: The animals entered the study straight after birth, being separated according to gender and randomly divided into CON (control, saline-treated) and MSG (monosodium glutamate-treated) groups. Next, the animals underwent LIPEC or sham-operated surgery (SHAM). Obesity was induced by the injection of MSG $(4 \mathrm{mg} / \mathrm{g} /$ day) during neonatal stage (2nd to 11th day from birth). LIPEC was performed on the 12th week, consisting in the withdrawal of parietal WAT. On the 16th week, the following WATs were isolated and collected: peri-epididymalWAT (EP-WAT); parametrial-WAT (PM-WAT); omental-WAT (OM-WAT); perirenal-WAT (PR-WAT) and retroperitonealWAT (RP-WAT).
\end{abstract}

Results: The adiposity index was significantly increased in both male $\left(3.2 \pm 0.2^{* *}\right.$ vs $\left.1.8 \pm 0.1\right)$ and female $\left(4.9 \pm 0.7^{*}\right.$ vs $2.6 \pm 0.3)$ obese rats compared to their respective control groups. LIPEC in obese animals produced fat accumulation in visceral fat sites in a more accentuated manner in female $\left(3.6 \pm 0.3^{* *}\right.$ vs $\left.2.8 \pm 0.3 \mathrm{~g} / 100 \mathrm{~g}\right)$ rather than in male $\left(1.8 \pm 0.2^{*}\right.$ vs $\left.1.5 \pm 0.1 \mathrm{~g} / 100 \mathrm{~g}\right)$ rats compared to obese non-lipectomized animals. Among the visceral WATs, the greater differences were observed between gonadal WATs of obese lipectomized rats, with higher accumulation having been observed in PM-WAT $\left(2.8 \pm 0.3^{*}\right.$ vs $\left.2.1 \pm 0.2 \mathrm{~g} / 100 \mathrm{~g}\right)$ rather than in EP-WAT $(1.0 \pm 0.1 \pm 0$. $9 \pm 0.1 \mathrm{~g} / 100 \mathrm{~g}$ ) when compared to obese non-lipectomized animals.

Conclusions: The results of the present study led us to conclude that obesity induced by MSG treatment occurs differently in male and female rats. When associated with parietal LIPEC, there was a significant increase in the deposition of visceral fat, which was significantly higher in obese female rats than in males, indicating that fat mobility among WATs in lipectomized-obese rats can occur more expressively in particular sites of remaining WATs.

Keywords: Obesity, Lipectomy, White adipose tissue, Monosodium glutamate

\footnotetext{
* Correspondence: hmauad@terra.com.br

${ }^{1}$ Department of Physiological Sciences, Health Sciences Center, Federal

University of Espírito Santo, Av. Marechal Campos 1468, Vitória, ES CEP

29042-751, Brazil

Full list of author information is available at the end of the article
}

(c) The Author(s). 2019 Open Access This article is distributed under the terms of the Creative Commons Attribution 4.0 International License (http://creativecommons.org/licenses/by/4.0/), which permits unrestricted use, distribution, and reproduction in any medium, provided you give appropriate credit to the original author(s) and the source, provide a link to the Creative Commons license, and indicate if changes were made. The Creative Commons Public Domain Dedication waiver (http://creativecommons.org/publicdomain/zero/1.0/) applies to the data made available in this article, unless otherwise stated. 


\section{Background}

Obesity has become a major public health challenge [1], for the prevalence of overweight and obese people has been increasing worldwide, being related to alarming epidemiological risk factors for diabetes, cardiovascular disease, cancer and premature death [2]. The genesis of obesity and its physiological consequences have been extensively studied. Our particular interest lies in understanding the mobility of fat deposited in adipocytes among different fatty territories, which could play a crucial role in the pathogenesis of obesity-related diseases.

Specific conditions such as gender, blood circulation, neurological factors and obesity itself could account for the local differences observed among different fat depots regarding cellular composition, size and function, making them act as "separate miniorgans" [3].

It is well known that the fat stored in adipocytes is not homogeneous. Its distribution among the different white adipose tissue (WAT) depots affects the production of inflammatory cytokines and chemokines by pre-adipocytes, which is also influenced by age and body weight [3-5]. The bulk of the body's fat resides in subcutaneous WAT depots, which can be distinctive due to unique metabolic and physiological characteristics. Also known as parietal WAT, these subcutaneous fat depots are located mainly in the inferior portion of the body, where they protect the muscles from fat infiltration by capturing the excess of lipids, contributing also to glucose homeostasis as metabolic dissipators [6]. On the other hand, it is widely known that upper-body adiposity constitutes an important risk factor for many diseases, with visceral adiposity playing a major role in metabolic disorders, including insulin resistance, hyperinsulinemia, type- 2 diabetes mellitus, among others [7-10]. Therefore, knowing the precise location and amount of the different fat depots in one's body is critical for the comprehension of the actual role of regional adiposity as a risk factor in epidemiological studies [11].

Due to culturally-defined beauty standards, surgical removal of WAT through liposuction has been widely employed. It consists in the withdrawal of accumulation and/or bad distribution areas of parietal WAT, mainly from the deep layer (lamellar). This procedure has also been employed experimentally through parietal LIPEC, presenting controversial results concerning compensatory increases of WAT and the mobility of lipids among fat territories. This controversy is observed in both experimental $[12,13]$ and clinical studies [14-17]. Strong evidence points to changes taking place in the parietal WAT after its resection, including fat deposition in non-lipectomized areas. However, which are these areas, how do they behave after parietal LIPEC and are these issues influenced by gender are questions that remain to be fully answered.

In order to assess these issues, we employed an experimental model in which obesity was induced by treating neonatal rats with monosodium glutamate (MSG). MSG provokes damage in the central nervous system (CNS), predominantly in the hypothalamus arcuate nucleus (HAN), which is highly involved in the release of neurotransmitters, peptides and hormones [18-21]. HAN lesions occurring during the neonatal period lead to several neuro-endocrine changes in the regulation of food intake in rats, resulting in decreased naso-anal length, hyperlipidemia and, above all, obesity [22, 23]. In addition, it has been reported that adult rats treated with MSG displayed hyperinsulinemia, pointing to an impairment of insulin sensitivity [24].

Despite the many results achieved so far on the connection between MSG treatment and obesity, the occurrence of fat mobility among WATs in this experimental model remains to be addressed, particularly following LIPEC in obese rats. Thus, the aim of this study was to investigate which of the remaining fat pads assume the key role of accumulating lipids after surgical removal of parietal WAT in rats of both sexes displaying MSG-induced obesity.

\section{Methods \\ Animal models and ethical issues}

Male and female Wistar rats - included in the study straight after birth - were maintained on a standard diet and tap water, being exposed to a $12 / 12 \mathrm{~h}$ light-dark cycle at $23^{\circ} \mathrm{C}$. First, the animals were separated according to gender and randomly divided into the following groups: CON (control, saline-treated, male/female $n=11 / 10$, respectively) and MSG (monosodium glutamate-treated male/female $n=15$ / 16, respectively). Next, the animals underwent (LIPEC) or sham-operated surgery (SHAM), comprising the following groups: males CON-LIPEC $(n=4)$, CON-SHAM $(n=7)$, MSG-LIPEC $(n=10)$ and MSG-SHAM $(n=5)$; females CON-LIPEC $(n=5)$, CON-SHAM $(n=5)$, MSG-LIPEC $(n=11)$ and MSG-SHAM $(n=5)$.

All experiments were conducted in accordance with the U.S. National Institute of Health Guidelines for the Care and Use of Laboratory Animals, and study protocols were previously approved by our Institutional Ethics Committee for the Use of Animals (Protocol \# 034/2011).

\section{Obesity-inducing treatment}

Obesity was induced by subcutaneous injection of MSG (4 $\mathrm{mg} / \mathrm{g} /$ day) during neonatal stage (2nd to 11th days from birth). Control animals were submitted to the same schedule of injections, receiving $\mathrm{NaCl}$ hypertonic solution (1.45\%) instead. At the age of 21 days, animals were weaned and placed in polypropylene boxes. All animals received the same standard diet ad libitum throughout the study.

\section{Surgical procedures}

LIPEC was performed on the 12th week under anesthesia with chloral hydrate $10 \%$, intraperitoneally. 
With the animals positioned in dorsal decubitus, the skin of the inguinal region and a small notch from the midpoint of the thigh to the knee joint of the animals were pinched. Then, a divulsion was performed for the detachment of WAT from the aponeurotic structures and the skin, and also for the detachment of the adipose projection on the flanks until the reflection between the ventral abdomen and the back-lobe and posterior withdrawal of parietal WAT. The skin was then sutured with 4-0 cotton yarn, by continuous scrubbing. Removal of the parietal WAT was done bilaterally and weighed on a precision scale. Sham surgery consisted in surgical incision and cotton suture only.

On the 16th week, the WATs were isolated and collected from the following sites: parietal WAT (PT-WAT), only in animals non-lipectomized at the 12th week; perigonadal-WATs: peri-epididymal-WAT (EP-WAT) and parametrial-WAT (PM-WAT); omental-WAT (OM-WAT), which corresponds to the greater omentum; perirenal-WAT (PR-WAT) and retroperitoneal-WAT (RP-WAT).

Firstly, animals were decapitated and submitted to tricotomy in the abdominal anterior region and antero-medial rear paws. Next, animals were fixed in a surgical board in supine position. The individual procedures for the removal of each particular WAT are briefly described below:

\section{Parietal-WAT}

This procedure - performed only in sham groups (CON-SHAM and MSG-SHAM) - was conducted as described above for the animals lipectomized at the 12th week.

\section{Perigonadal-WATs}

Initially, for male rats, a medium pubic xiphoid opening and a perigonadal adipose cushion were clamped. This tissue was then pulled for testicular exposure and individualization of peri-epididimal fat planes. In female rats, the uterus was pulled and sections of parametrial-WAT projections were performed.

\section{Omental-WATs}

This tissue was collected after traction of the spleen and the stomach, exposing the greater curvature of the latter for resection of the greater omentum.

\section{Perirenal-WAT}

It was collected by bouncing the intestines laterally for visualization of the kidney and its perirenal fat. By tractioning the kidney, the limits of this fat pad are exposed and excised. This procedure was performed bilaterally.

\section{Retroperitoneal-WAT}

After renal resection and subsequent removal of the perirenal-WAT and the adrenal gland, retroperitoneal fat is easily visualized. It was resected from the pelvic region up to below the diaphragm insertion, bilaterally.

\section{Data analysis}

Considering the variation in the total body weight of the animals, all the WATs obtained (g) were normalized by $100 \mathrm{~g}$ of body weight. The sum of all WATs - but the parietal-WAT that was removed in the 12th week - is referred to as "total fats". The Adiposity Index was calculated by the sum of total fats divided by corporal weight and multiplied by 100 , representing the amount of fat from all WATs aforementioned by grams of animal. The term "Visceral WAT" refers to the quantity of fat accumulated in the viscera. It comprises the sum of omental-, perirenal and epididymal-/parametrial-WATs. Extra-Visceral WAT represents the fat accumulated in the abdomen, but not in the viscera. It was obtained by the sum of retroperitoneal- and parietal-WATs, except in those cases where parietal fat was removed.

\section{Statistical analysis}

The results are expressed as the mean \pm SEM. For the evaluation of the normality of the data distribution we used the D'Agostino and Pearson test. In addition, all data were submitted to two-way analysis of variance (ANOVA) followed by Tukey test, and, for some of the data, to the Student's t-test. Statistical significance was achieved when $p<0.05$.

\section{Results}

Anthropometric parameters of the different groups studied are shown in Table 1. After 16 weeks, both MSG-treated groups presented body weight values smaller than those of CON groups, which was true for both sexes (although for sham females the change was not statistically significant). On the other hand, we observed that the LIPEC procedure did not induce changes in body weight in either CON or MSG-treated animals, which, again, was true for males and females. It is worthy of note that female animals weighted less than males to begin with. These results clearly show that MSG treatment induced less body weight gain in both male and female animals, with LIPEC having no effects on this parameter.

In order to evaluate actual fat accumulation in the animals from all groups, we determined the parameter total fat (Table 1). We observed that, while LIPEC significantly increased the total fat in MSG-LIPEC male rats when compared to CON-LIPEC animals, no significant differences were observed regarding this parameter when animals belonging to MSG-LIPEC and MSG-SHAM groups were compared between themselves, as well as between CON-LIPEC and CON-SHAM groups. On the other hand, LIPEC induced opposite effects regarding 
Table 1 Anthropometrics parameters of animals

\begin{tabular}{lllll}
\hline & CON-SHAM & CON-LIPEC & MSG-SHAM & MSG-LIPEC \\
\hline & Male & & & \\
Body Weight (g) & $380 \pm 16$ & $412 \pm 4$ & $275 \pm 6^{* *}$ & $294 \pm 12^{\# \#}$ \\
Total Fat (g) & $6.8 \pm 0.7$ & $7.3 \pm 0.7$ & $8.9 \pm 0.8$ & $9.9 \pm 0.5^{\#}$ \\
Adiposity Index & $1.8 \pm 0.1$ & $1.8 \pm 0.2$ & $3.2 \pm 0.2^{* *}$ & $3.2 \pm 0.2^{\#}$ \\
& Female & & & \\
Body Weight (g) & $244 \pm 6$ & $244 \pm 4$ & $203 \pm 13$ & $185 \pm 4^{\# \#}$ \\
Total Fat (g) & $6.3 \pm 0.7$ & $5.2 \pm 0.3^{* *}$ & $9.3 \pm 1.2^{*}$ & $10.2 \pm 1.1^{\# \#+十}$ \\
Adiposity Index & $2.6 \pm 0.3$ & $2.1 \pm 0.2$ & $4.9 \pm 0.7^{*}$ & $5.5 \pm 0.5^{\# \#}$ \\
\hline
\end{tabular}

${ }^{*} p<0.05$ e ${ }^{* *} p<0.01$, different to CON-SHAM group. ${ }^{*} p<0.05$ e ${ }^{\# \#} p<0.01$, different to CON-LIPEC group. ${ }^{\dagger} p<0.05$ e ${ }^{t+} p<0.01$, different to MSG-SHAM group. ANOVA 2 way, post hoc: Tukey

total fat accumulation in CON and MSG-treated female rats: while the procedure led to smaller total fat values in CON animals, significantly higher values were found in MSG-treated rats. In fact, total fat values in MSG- LIPEC female rats were significantly higher than those of either MSG-SHAM and CON- LIPEC animals. These results clearly show that there is greater accumulation of total fat in obese female rats when compared to males, and that LIPEC potentiated this accumulation.

Considering that the procedures employed, i.e., LIPEC and MSG treatment, produced different changes in the body weight parameter, we have also analyzed their effects on the adiposity index of the animals (Table 1), which permitted us to compare values of fat per gram of corporal weight among the groups. We observed that MSG-treated male rats - LIPEC or not - presented significantly higher adiposity indexes when compared to their respective controls, which was also true for female rats. Taken together, these results indicate that MSG-induced obesity led to a more pronounced fat accumulation in females, with this accumulation being even higher when obesity was associated with LIPEC.

We then asked ourselves how the distribution of fat in different corporal regions occurs after LIPEC, in both control and obese animals. To answer that, we separated groups of WATs based on their anatomical localization and functional aspects. To begin with, we considered the group deemed visceral WAT (Fig. 1). We observed that, in males, while there was a significant increase in visceral WAT in obese animals submitted to LIPEC when compared to lipectomized control animals, obesity alone did not have a significant effect (Fig. 1a). On the other hand, in female animals, we observed that obesity alone produced a significant increase in visceral WAT when compared to the sham control group. Moreover, obesity associated to LIPEC induced significantly higher increases in visceral WAT not only compared to lipectomized control animals but also to no LIPEC obese ones (Fig. 1b). These data strongly indicate that the effects of
LIPEC on visceral WAT accumulation are much more severe in obese female rats than in obese males.

Next, we assessed the individual contribution of each one of the WATs that compose the visceral fat (Fig. 2). We did not observe significant differences regarding the OmentalWAT in male rats (Fig. 2a). In females, we observed increased fat accumulation in both obesity-induced groups when compared to their respective controls (Fig. 2b).

As to Perirenal-WAT, we observed, for both sexes, that lipectomized obese animals presented higher fat accumulation values when compared to lipectomized control animals, with obesity by itself showing no significant effects (Fig. 2).

Finally, regarding Gonadal-WATs, we observed increased values of Periepididymal WAT in lipectomized obese animals when compared to their lipectomized controls (Fig. 2e). Parametrial WAT values, on the other hand, were found to be significantly higher in both MSG groups when compared to their respective controls, as well as when obese lipectomized animals were compared to obese non-lipectomized animals (Fig. 2f). Taken together, these results suggest that the higher accumulation of visceral WATs observed in female rats is mainly due to an increase in Parametrial WAT in obese animals, particularly in those submitted to LIPEC.

We have also dwelt upon the differences between extravisceral and extraabdominal fat accumulation, through the analysis of retroperitoneal- and parietal-WATs (Table 2). We observed that, for both sexes, obesity itself induced higher retroperitoneal and parietal fat accumulation when compared to control animals. In obese female rats, LIPEC induced a significantly higher accumulation of retroperitoneal fat, clearly indicating that post-LIPEC fat mobility to this pad is gender-dependent. It is important to point out that, as in both lipectomized groups the parietal values are relative to the 12th week, while in sham-operated groups these values are relative to the 16th week, one should indeed expect no significant differences among animals undergoing the procedure with regards to their respective controls.

The mobility of fat among WATs after MSG-induced obesity alone or associated to the removal of parietal WAT through LIPEC was then evaluated. In order to assess this parameter, we first calculated the relative percentage of each WAT collected at the 16th week in relation to normalized values of total fat from the same animal, except for parietal-WAT, which was considered only in non-lipectomized animals. First of all, we observed that in male rats (Fig. 3a) obesity alone (MSG-SHAM) did not yield significant changes in fat accumulation among the different territories. On the other hand, LIPEC alone (CON-LIPEC) was able to drive major accumulation of fat in perirenal, periepidydimal and retroperitoneal WATs compared to non-lipectomized control animals (CON-SHAM). 

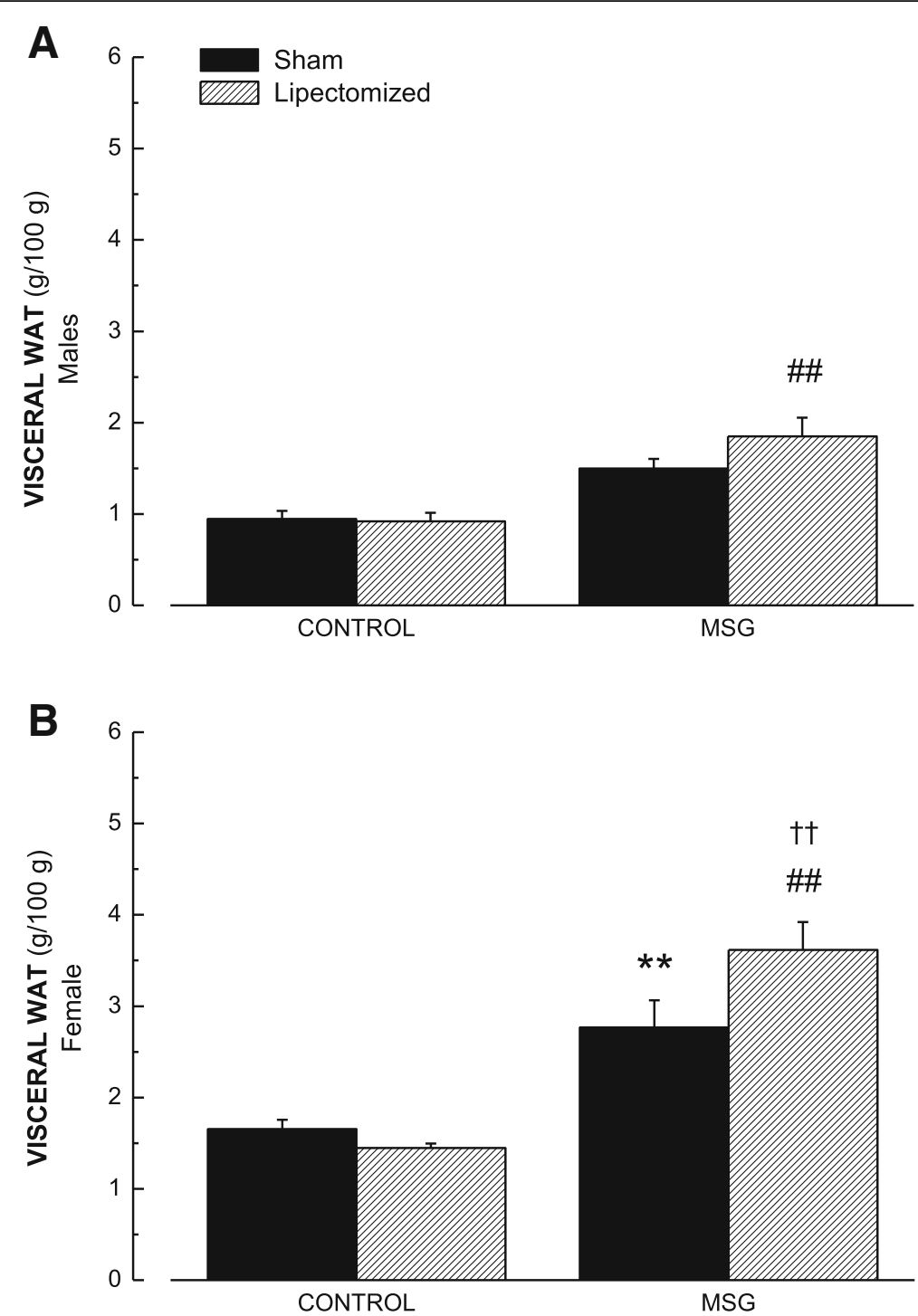

Fig. 1 Values of Visceral Fat in CON-LIPEC, CON-SHAM, MSG-LIPEC and MSG-SHAM) groups in male (a) and female (b) rats. ${ }^{* *} p<0.01$ compared to respective CON-SHAM. ${ }^{\# \#} p<0.01$ compared to CON-LIPEC. ${ }^{+\dagger} p<0.01$ compared to MSG-SHAM

When associated to obesity (MSG-LIPEC vs MSG-SHAM), we observed that LIPEC promoted crescent accumulation of fat among the following WATs: omental $(268 \%)>>$ perirenal $(86 \%)>$ periepidydimal $(84 \%)>$ retroperitoneal $(41 \%)$. These results indicate that while LIPEC, alone or associated to obesity, promotes proportionally distinct levels of fat accumulation in different WATs, obesity alone - in spite of inducing higher adiposity - led to fat distribution in a more uniform manner.

In female rats (Fig. 3b), we found that obesity alone led to proportionally higher levels of fat being distributed to perirenal and parietal WATs. LIPEC alone promoted a major percentage of fat accumulation in parametrial and retroperitoneal WATs when compared to non-lipectomized control animals. And, unlike in male rats, the effect of LIPEC associated to obesity yielded the following crescent proportional accumulation: parametrial $(85 \%)>$ omental $\quad(74 \%)>$ perirenal $(48 \%)>$ retoperitoneal $(25 \%)$, corroborating the results in which we observed major increased accumulation in visceral fat.

Finally, we analyzed the magnitude of the effects induced by LIPEC in both obese (MSG) and non-obese (control) groups (Fig. 4). We have done that by computing the difference in percentage of WATs in relation total fat between lipectomized and non-lipectomized animals. In male rats (Fig. 4a), we observed that LIPEC induced similar accumulation of fat in perirenal and periepidydimal WATs in both obese and non-obese animals, with the retroperitoneal WAT in obese rats being 
A

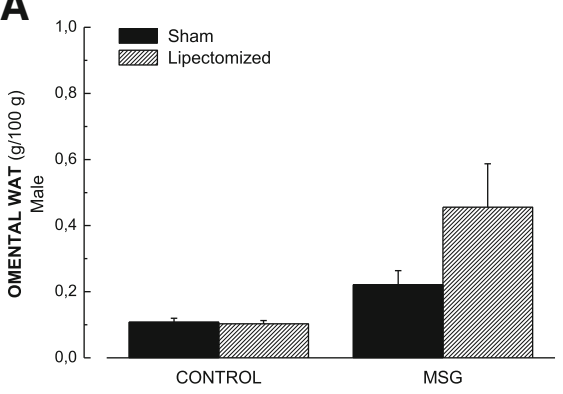

C

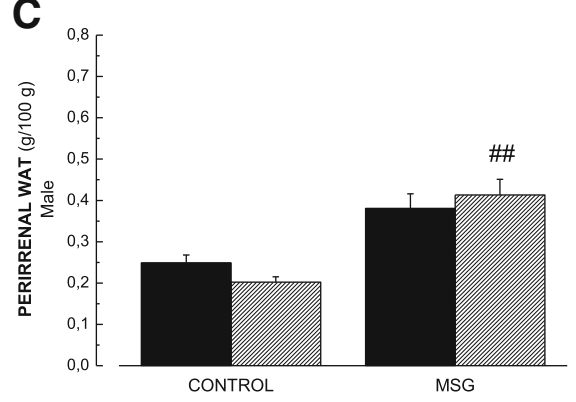

E

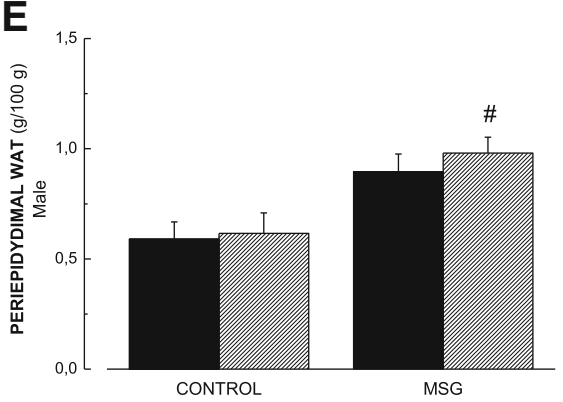

B

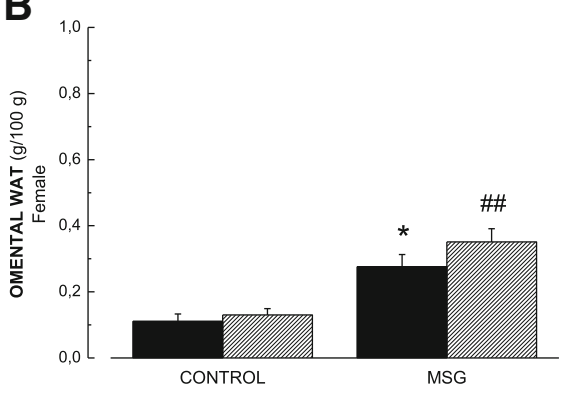

D

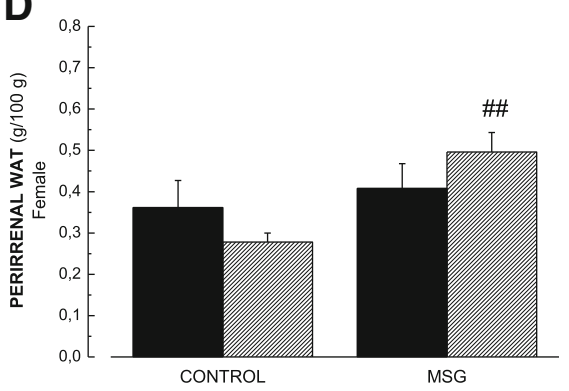

F

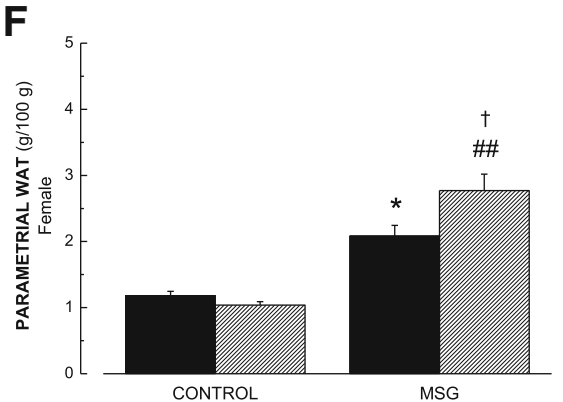

Fig. 2 Values of Omental WAT (a and $\mathbf{b}$ ), Perirenal WAT (c and $\mathbf{d}$ ) and Gonadal (Periepidydimal and Parametrial) WATs (e and $\mathbf{f}$ ) in CON-LIPEC, CON-SHAM, MSG-LIPEC and MSG-SHAM) groups in male and female rats. ${ }^{*} p<0.05$ and ${ }^{* *} p<0.01$ compared to respective CON-SHAM. ${ }^{*} p<0.05$ and ${ }^{\# \#} p<0.01$ compared to CON-LIPEC. ${ }^{\dagger} p<0.05$ compared to MSG-SHAM

significantly decreased by the procedure. The exact opposite was observed with regards to omental WAT, which was significantly increased by LIPEC in obese animals when compared to their controls. In female rats (Fig. 4b), we observed that LIPEC induced similar accumulation of fat in WATs of both control and MSG

Table 2 Retroperitoneal (Extravisceral) and Parietal (Extraabdominal) WATs of animals

\begin{tabular}{lllll}
\hline & CON-SHAM & CON-LIPEC & MSG-SHAM & MSG-LIPEC \\
\hline WAT (g/100 g) & Male rats & & & \\
Retroperitoneal & $0.84 \pm 0.06$ & $0.84 \pm 0.07$ & $1.72 \pm 0.17^{* *}$ & $1.34 \pm 0.14$ \\
Parietal & $1.17 \pm 0.06$ & $1.14 \pm 0.10$ & $2.48 \pm 0.28^{* *}$ & $3.27 \pm 0.19$ \\
& Female rats & & & \\
Retroperitoneal & $0.91 \pm 0.15$ & $0.69 \pm 0.05$ & $1.66 \pm 0.16^{*}$ & $1.84 \pm 0.23^{\# \#}$ \\
Parietal & $0.97 \pm 0.07$ & $0.95 \pm 0.06$ & $3.11 \pm 0.28^{*}$ & $3.57 \pm 0.68$ \\
\hline
\end{tabular}

${ }^{*} p<0.05$ e ${ }^{* *} p<0.01$, different to CON-SHAM group. ${ }^{\# \#} p<0.01$, different to CON-LIPEC group. ANOVA 2 way, post hoc: Tukey groups, except for parametrial WAT, which had significantly increased fat levels in obese animals in comparison to non-obese ones.

\section{Discussion}

The present study revealed that MSG-treatment induces obesity in male and female rats in different ways. It was shown that LIPEC in obese animals produced fat accumulation in visceral fat sites in a more accentuated manner in female than in male rats. In addition, we observed that among the visceral depots collected, the parametrial-WAT was the preferential one for lipid accumulation, indicating that fat mobility among WATs in lipectomized-obese rats can occur more expressively in specific depots of remaining WATs in a gender-dependent manner. However, the manner by which reminiscent territories of white adipose tissue behaves after LIPEC of subcutaneous WAT, as well as gender-related issues, is not yet completely understood. Therefore, in order to evaluate the effects of experimental 

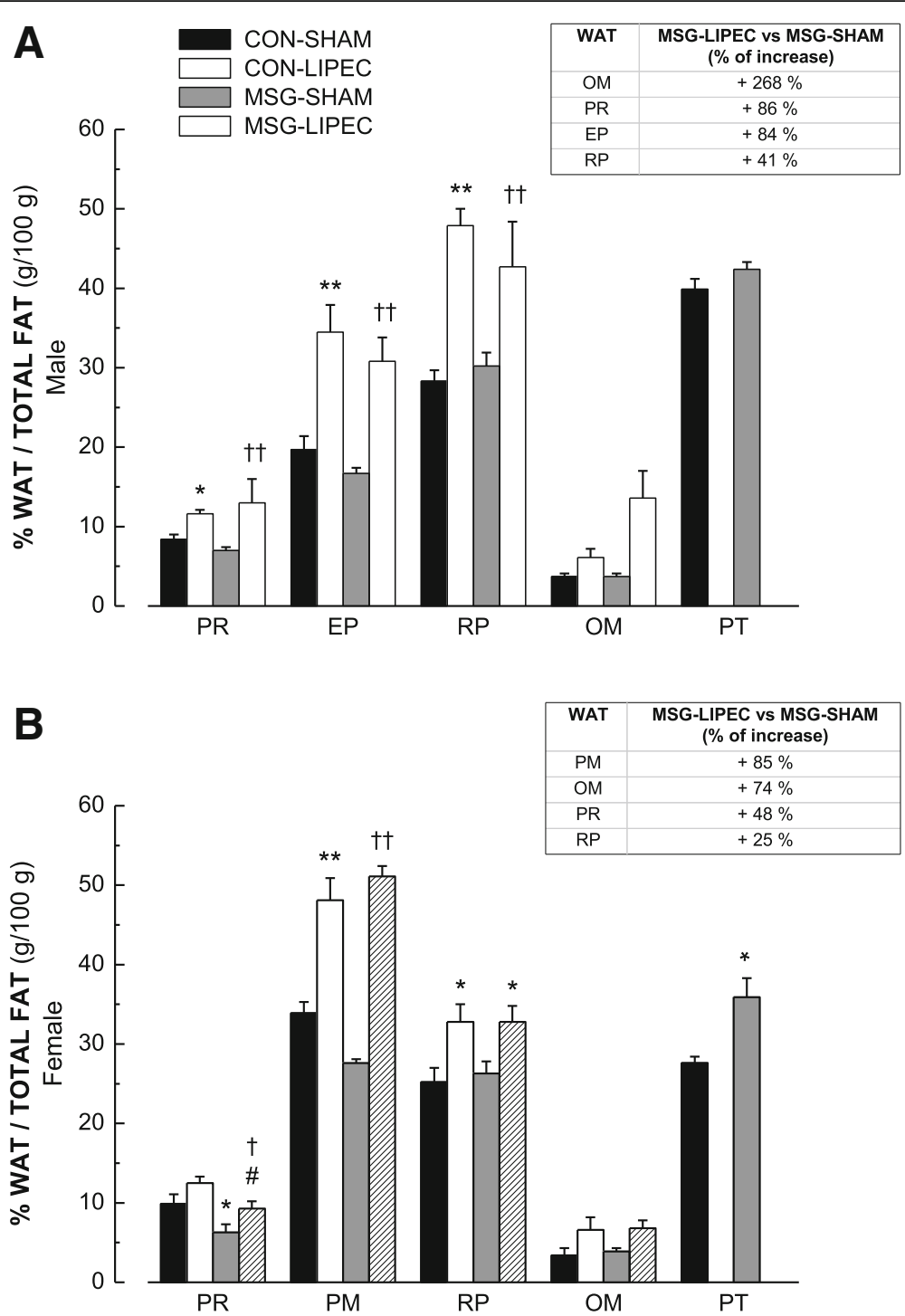

Fig. 3 Percentage of WAT in relation to total fat in CON-LIPEC, CON-SHAM, MSG-LIPEC and MSG-SHAM) groups in male (a) and female (b) rats. * $p<0.05$ and ${ }^{* *} p<0.01$ compared to respective CON-SHAM. ${ }^{*} p<0.05$ and ${ }^{\# \#} p<0.01$ compared to CON-LIPEC. ${ }^{\dagger} p<0.05$ and ${ }^{\dagger+} p<0.01$ compared to MSG-SHAM. WATs: PT, parietal; RP, retroperitoneal; EP, periepidydimal; PM, parametrial; PR, perirenal; OM, omental. Tables indicate percentage of increasing of WATs between MSG-LIPEC and MSG-SHAM groups

LIPEC (parietal WAT removal) on different territories of adipose tissue in males and females we employed the well-known MSG-induced obesity rat model. MSG model has been extensively used in obesity studies and has contributed effectively to the understanding of different aspects of this disease. [18-24]

Initially, we observed that animals submitted to MSG treatment actually weighed less than control animals. These results are corroborated by previous studies performed by Kizer et al. (1977) [25], in which they show that MSG administered in the neonatal phase does not produce significant increase in body weight, when compared with non-treated animals. In this obesity model, the animals MSG-treated presented an imbalance in the hypothalamic-pituitary-adrenocortical (HPA) axis and among several endocrine changes, Ranke et al. (1988) [26] reported a decreased production of growth hormone (hyposomatotropism). Decreasing of naso-anal length was also previously described in this obesity model by Pizzi and Branhart (1976) [27] and Nemeroff et al. (1977) [23]. However, this lower weight gain cannot be attributed as secondary to a lower food intake, since these same authors previously reported that the animals MSG-treated presented normophagia.

The development of obesity exhibiting normophagia is rather intriguing, because MSG provokes damage in the 

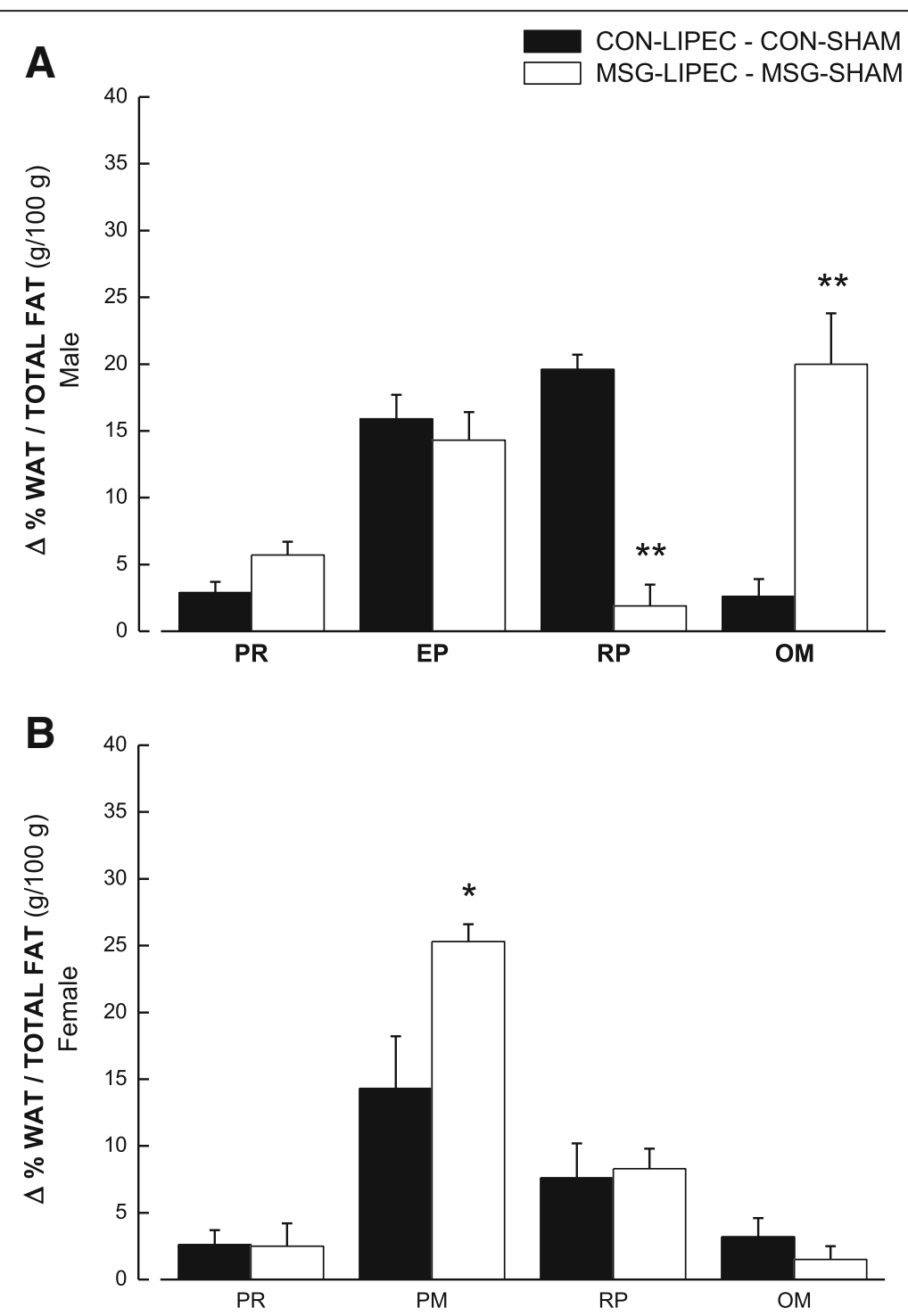

Fig. 4 Percentage changes of WAT in relation to total fat between control (CON-LIPEC minus CON-SHAM) and MSG (MSG-LIPEC minus MSGSHAM) groups in male (a) and female (b) rats. ${ }^{*} p<0.05$ and ${ }^{* *} p<0.01$ in relation to respective control group. WATs: RP, retroperitoneal; EP, periepidydimal; PM, parametrial; PR, perirenal; OM, omental

arcuate nucleus of hypothalamus (ANH), an important area in the control of orexigenic and anorectic mechanisms [18, 21, 28-34]. Studies of Shi et al. $(2007,35]$ observed different approaches to reduce fat mass by caloric restriction or surgical fat removal (LIPEC) male and female rats affected food intake behavior, which can implicate directly in the capability to restore visceral fat. In the present study, we did not quantify food intake, as normophagia is a consolidated eating behavior in this model. On the other hand, the installation of obesity was observed on other parameters, such as increased total fat and adipose index.

In relation to the adiposity index, we observed that this parameter was significantly increased in both
MSG-treated male and female rats. Surprisingly, the adiposity index was much higher (approximately 2 -fold) in females than in males. These data clearly show marked gender-dependent differences in the accumulation of fats in MSG-treated animals. In addition, we observed that LIPEC in non-obese animals does not significantly alter the adiposity index, i.e., it does not induce obesity.

The total fats in the present study represent the sum of all WAT territories evaluated by us. In our study, this parameter permitted the evaluation of fat mobility in different WAT territories after LIPEC in obese animals. One of our main findings was the significantly higher visceral WAT accumulation in obese females than in obese males, which were submitted to LIPEC. 
There are yet great controversy about the distribution and/or accumulation of lipids in the reminiscent WAT depots after LIPEC, as well as in relation the mechanisms involved, mainly when analyzed the influence of gender. Different from our findings, previous studies performed by Shi et al. (2007) [35] observed that female mice had a reduced capability to restore visceral fat (retroperitoneal depots) after fat loss by LIPEC. A possible reason for this discrepant result could be explained by the fact that we evaluate several visceral WAT depots and tried to evaluate the association of obesity and parietal LIPEC in the rat model. However, it is important to emphasize that we choose the withdrawal of parietal subcutaneous WAT depots because this has also been a routine in humans.

When focusing the metabolic role of different regions of the body adipose tissue, cumulative data from the last decades of research consolidated the notion presented in 1947 by Vague [36] that obesity is not a homogeneous condition. Others have suggested that the data regional distribution of adipose tissue is important for the understanding of obesity and its correlation with metabolic disorders of glucose and lipids [37]. Several studies have shown that the harmful influence of obesity on metabolic processes is mediated by intra-abdominal fat deposition. In this sense, visceral fat has been correlated with glucose intolerance and associated with hyperinsulinemia during the oral glucose tolerance test, suggesting a clinical picture of insulin resistance [38-41] as has been evidenced by studies about the effects of neonatal MSG administration on insulin resistance. The increase in the adiposity of these animals was believed to be secondary to the increase in sympathetic hypothalamic activity, which decreases the transport of GLUT-4 in brown adipose tissue (BAT), consequently decreasing thermogenesis [42]. These effects could even be justified by the decrease of NPY levels in areas such as ANH and paraventricular nucleus (PVN) in the hypothalamus [43]. However, a more plausible hypothesis is related to glucose metabolism, since the increased sympathetic activity in visceral adipose depots seems too produce lipolysis and lipid mobilization by activating of $\beta_{3}$-adrenoceptors (see Fig. 5). Previous studies in humans, showed that the lipolytic $\beta_{3}$-adrenoreceptor sensitivity was 12 times higher in men, and the antilipolytic $\alpha_{2}$-adrenoreceptor sensitivity was 17 times lower in men, which lead us to conclude that in obesity, the catecholamine-induced rate of lipid mobilization from visceral fat is higher in men than women [44].

Nevertheless, the role of brown adipose tissue and its effects to thermogenesis cannot be ruled out. Adipocytes from obese patients are characterized by altered endocrine function, which leads to increased secretion of proinflammatory adipokines [45-47]. The activation of inflammatory pathways leads to insulin resistance in peripheral tissues, such as skeletal muscle and adipose tissue itself [48]. Only in the last decade, that skeletal muscle has been shown to behave an active endocrine organ that releases myokine, which is described as being able to communicate with cells in a local autocrine/paracrine manner within the muscles, or endocrine to distant tissues [49-51]. Myokines, peptides secreted by the muscles, are also produced by adipose tissue, activating thermogenesis in the brown adipose tissue in vitro and in vivo and participating in some metabolic functions and energy dissipation in these cells. Obese animals show higher expression of this peptide, suggesting some level of resistance to its effects [52, 53]. Perhaps, this could explain why, in the present study, LIPEC did not alter weight, total fat or adiposity index until the 16th week (when the animals were sacrificed) in non-obese animals, contrasting with what was observed in MSG-treated obese animals.

The novelty of the present study is the reporting of a significant increase in deposition the visceral WATs of lipectomized obese females compared non-lipectomized ones. To permit the discussion of our findings, we portrayed in Fig. 5 some possible mechanisms involved in the "Endocrine Regulation of Visceral Adipose Tissue" in MSG-treated animals.

Studies performed by Macho et al. (2000) [54] showed that early postnatal administration of MSG had an important effect on glucose metabolism and insulin action in adipocytes when the animals reached adulthood, where increases in insulin, glucose and leptin levels have been observed. Then, it would be plausible to assume that a possible hyperinsulinemia in MSG-treated animals could accentuate insulin lipogenic effects, inducing higher lipids synthesis and deposition into the adipocytes, contributing to the increased total fat and adiposity index observed in our study.

However, we believe that fat deposition in MSG-treated animals is more complex, and possibly due to multifactorial effects. In this regard, the effects of female hormones on WAT, particularly estradiol, should also be considered. Previous studies have shown that the weekly assessment of body weight revealed a significant increase in weight gain of ovariectomized females compared to non-ovariectomized females $[55,56]$. It has been proposed by Naaz et al. (2002) [57] that adipose tissue is highly responsive to estrogen via receptors (ER) alpha and beta (ER- $\alpha$ and ER- $\beta$ ), with a more important role for ER- $\alpha$ in this tissue. Heine et al. (2000) [58] have previously suggested that estrogen regulates the amount of white adipose tissue through ER- $\alpha$ in an inhibitory way, and the absence of this receptor would cause adipocyte hypertrophy and hyperplasia, insulin resistance and glucose intolerance in both sexes. Birth studies conducted in 1991 reported that there was a sex-dependent response in 


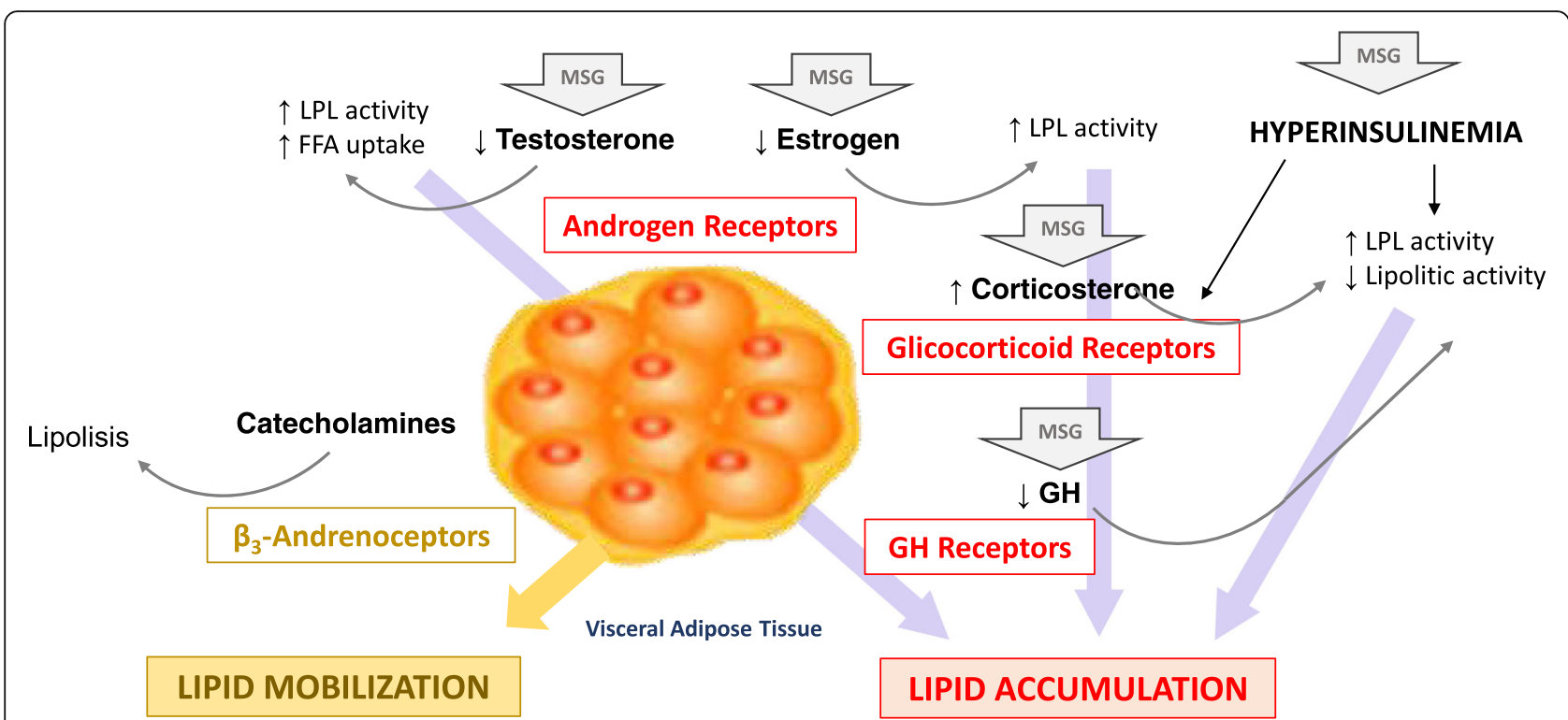

Fig. 5 Mechanism of endocrine regulation of visceral adipose tissue in MSG-treated animals. Lipoprotein lipase, LPL; Free fat acid, FFA, monosodium glutamate, MSG and growth hormone, GH. MSG in arrows indicate hormonal changes observed in animals MSG-treated

the development of obesity through glutamate [59]. One of the possibilities would be due to obese females presenting a significant decrease in ovarian and uterine weight with consequent reduction in the number of primordial and Graafian follicles, with decrease of estradiol $\left(\mathrm{E}_{2}\right)$ levels culminating in obesity and decreased body growth [60]. In fact, decreased levels of $E_{2}$ have been found in MSG-treated obese rats [61]. In addition, $E_{2}$ has shown a protective effect on insulin resistance $[62,63]$, as well as antidiabetic and auxiliary effects on body weight reduction even under a high-fat diet in rats [64]. Studies performed by Curi et al. (1991 [65] about neuroendocrine functions in neonatal MSG-treated rats evaluate possible alterations in lipogenesis rate and lipoprotein lipase (LPL) activity. These authors observed in female rats, increased lipogenesis in gonadal and retroperitoneal adipose tissues, while in male rats it was observed only in retroperitoneal adipose tissue. In addition, in female rats the administration of LPL inhibitor did not change retroperitoneal lipogenesis, suggesting that there is a specific sex-dependent response in the development of MSG-induced obesity. Although multifactorial, the extreme adipocyte mobility after LIPEC observed in our studies could be related to hypoestrogenism, as has been previously demonstrated in this model by Shen et al. (2014) [66].

On the other hand, the visceral adipose tissue has high density of androgen receptors and testosterone, which one can amplify its effect through upregulation of androgen receptors, inhibiting the expression of LPL and uptake of free fat acid (FFA). In men, visceral adipose tissue is negatively related to total and free plasma level of testosterone and by concentration of sex-hormone binding globuline (SHBG) [67]. Recent studies, have reported an interaction between glucocorticoid receptors and androgen receptors. The idea is that there is a "crosstalk" between these receptors in target tissues, like WAT and BAT. It was related that the androgen signal modulates transcriptional production of glucocorticoid receptors in a specific manner, i.e., the androgen receptor stimulation potentiated the transcriptional response to glucocorticoid receptor in vivo and in vitro in WAT and BAT, while the antagonism attenuated the signalization in both tissue [68]. Taking altogether, these studies appear to support the hypothesis that the deficiency of testosterone in male rats MSG-treated could contribute to accumulation of visceral adipose tissue. This low level of testosterone was demonstrated in studies performed by Ochiogu et al. (2015) [69].

Glucocorticoid receptors are considered those of the most important for human adipose tissue, and present an elevated density in visceral adipose tissue [70]. Previous studies reported by Bjorntorp, (1991) [71] showed that cortisol increases LPL activity and decreases lipolytic activity. In the Cushing's disease, the important pathogenetic factor for visceral fat accumulation is observed the enhanced cortisol secretion resulting from a hyperactivity of HPA axis [72]. However, this increased lipid accumulation also depends, in addition to the excess of glucocorticoids, of the state of insulin resistance and decreased growth hormone (GH) levels [73]. In our study, all these changed levels hormones are present in MSG-model [26, 74-76], which could effectively induce to visceral lipid tissue accumulation. In addition, due to a major density of the glucocorticoid receptors are found in visceral than in other adipose tissues, is expected that 
the lipid-accumulating effect of cortisol would be more pronounced in visceral than in other fat areas [71].

The effects of GH on the regulation of visceral fat have to be considered separately. A decrease in circulating GH was previously demonstrated in human obesity and it was associated to an increase in visceral fat [71, 77]. Otherwise, a reduction in visceral adipose tissue was observed in humans with acromegaly, a state of GH excess [78]. Thus, most action of GH on adipose tissue are to prevent lipid accumulation and to stimulate lipid mobilization. However, the regulation of adipose tissue metabolism requires synergism with steroid hormones, and in relation to lipid accumulation, LPL is markedly inhibited by GH in the presence of either testosterone or cortisol [71]. Considering that their receptors are particularly dense in visceral adipose tissue, a more pronounced effect of GH would be expected in this tissue [71]. In this way, an important hallmark of MSG model is the GH deficiency, which, in turn, would be considered one of major factor to induce visceral fat accumulation, obviously in synergism to other changed hormonal factors above described.

Summarizing, low levels of estrogen/testosterone, deficiency of GH and increased secretion of corticosterone, which has been observed in MSG-treated rats, could induce higher visceral fat accumulation. In female rats MSG subjected to back of estrogen could justify why paramentrial-WAT is more responsive to lipid accumulation, as has been observed in women in postmenopause, when abdominal fat cell present high LPL activity.

The need to feel good about how we look is part of the human condition. Overweight and obesity usually lead the population to adopt miracle diets to lose weight or treat associated illnesses such as dyslipidemias and diabetes. On the other hand, "nutraceuticals" and "functional foods" has been frequently used as an alternative biological intervention to pharmacological methods [79-82]. Chen et al. (2008) [83] that reported the beneficial Influences of red mold rice (RMR) on obesity and dyslipidemia. Some evidences have been showed that Dietary polyphenols (DPs) are effective and promote health via multiple signalling pathways (such as lipid anabolism/catabolism pathways, apoptotic pathways) [84]. A combined treatment with genestein, quercetin, and resveratrol was shown higher inhibition of adipogenesis in both primary human adipocytes and 3 T3-L1 murine adipocyte than individual molecules [85]. In the near future, nutraceutical or functional foods, might be associated to pos-surgery procedures, as LIPEC, to prevent obesity, by the risk factor of health that could be entailed.

\section{Conclusions}

The results of the present study led us to conclude that obesity induced by MSG treatment occurs differently in male and female rats. When associated with parietal LIPEC, there is a significant increase in the deposition of visceral fat, which is significantly higher in obese female than in male rats. Finally, these results allow us to infer that visceral WAT does not behave as a single tissue.

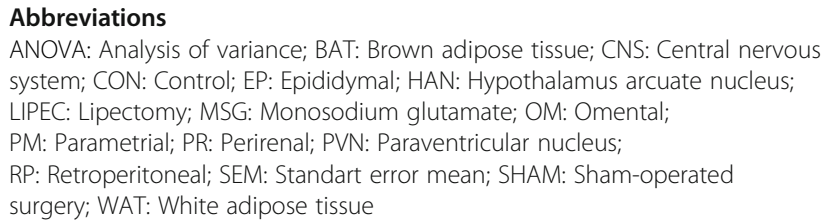

\section{Acknowledgements}

Not applicable

Funding

No funding

Availability of data and materials

All data generated or analyzed in this study are included in this manuscript.

\section{Authors' contributions}

FSP, HT and HM conceived and designed the experiments; FSP, HT, EWJ and HM performed the experiments; FSP, EWJ, MRHC, FVC, ECV and HM analyzed the data; FSP, FVC, ECV and HM wrote the paper. All authors read and approved the final manuscript.

Ethics approval and consent to participate

All experiments were conducted in accordance with the U.S. National Institute of Health Guidelines for the Care and Use of Laboratory Animals, and study protocols were previously approved by our Institutional Ethics Committee for the Use of Animals (Protocol \# 034/2011).

Consent for publication

Not applicable.

\section{Competing interests}

The authors declare that they have no competing interests.

\section{Publisher's Note}

Springer Nature remains neutral with regard to jurisdictional claims in published maps and institutional affiliations.

\section{Author details}

${ }^{1}$ Department of Physiological Sciences, Health Sciences Center, Federal University of Espírito Santo, Av. Marechal Campos 1468, Vitória, ES CEP 29042-751, Brazil. Laboratory of Translational Physiology and Pharmacology, Pharmaceutical Sciences Graduate Program, Vila Velha University (UW), Avenida Comissário José Dantas de Melo, 21 Bairro Boa Vista II, Vila Velha, ES CEP 29102-920, Brazil. ³Departament of Medical Clinic, Escola Superior de Ciências da Santa Casa de Misericórdia de Vitória (EMESCAM), Av. Nossa Sra. da Penha, 2190 - Bela Vista, Vitória, ES CEP 29027-502, Brazil. ${ }^{4}$ Faculdade Estácio, Av. Dr. Herwan Modenese Wanderley, 1001. Bairro Jardim Camburi, Vitória, ES CEP 29092-095, Brazil. ${ }^{5}$ Sports Department, Center for Physical Education and Sports, Federal University of Espírito Santo, Avenida Fernando Ferrari, 514. Bairro Goiabeiras, Vitória, ES CEP 29075-910, Brazil.

Received: 16 November 2018 Accepted: 24 January 2019

Published online: 09 February 2019

\section{References}

1. Kelly T, Yang W, Chen CS, Reynolds K, He J. Global burden of obesity in 2005 and projections to 2030. Int J Obes. 2008;32(9):1431-7.

2. Haslam DW, James WP. Obesity Lancet. 2005;366(9492):1197-209.

3. Tchkonia T, Thomou T, Zhu Y, Karagiannides I, Pothoulakis C, Jensen MD, Kirkland JL. Mechanisms and metabolic implications of regional differences among fat depots. Cell Metab. 2013;17(5):644-56. 
4. Cartwright MJ, Schlauch K, Lenburg ME, Tchkonia T, Pirtskhalava T, Cartwright A, Thomou T, Kirkland JL. Aging, depot origin, and preadipocyte gene expression. J Gerontol A Biol Sci Med Sci. 2010;65(3):242-51.

5. Tchkonia T, Morbeck DE, Von Zglinicki T, Van Deursen J, Lustgarten J, Scrable H, Khosla S, Jensen MD, Kirkland JL. Fat tissue, aging, and cellular senescence. Aging Cell. 2010;9(5):667-84.

6. Cox-York K, Wei Y, Wang D, Pagliassotti MJ, Foster MT. Lower body adipose tissue removal decreases glucose tolerance and insulin sensitivity in mice with exposure to high fat diet. Adipocyte. 2014;4(1):32-43.

7. Björntorp P. Visceral obesity: a "civilization syndrome". Obes Res. 1993;1(3):206-22.

8. Kissebah AH, Krakower GR. Regional adiposity and morbidity. Physiol Rev. 1994;74(4):761-811.

9. Després JP, Lemieux I. Abdominal obesity and metabolic syndrome. Nature. 2006;444(7121):881-7.

10. Van Gaal LF, Mertens IL, De Block CE. Mechanisms linking obesity with cardiovascular disease. Nature. 2006;444(7121):875-80.

11. Makrogiannis S, Caturegli G, Davatzikos C, Ferrucci L. Computer-aided assessment of regional abdominal fat with food residue removal in $C T$. Acad Radiol. 2013;20(11):1413-21.

12. Michel C, Cabanac M. Lipectomy, body weight, and body weight set point in rats. Physiol Behav. 1999;66(3):473-9.

13. Lacy EL, Bartness TJ. Effects of white adipose tissue grafts on total body fat and cellularity are dependent on graft type and location. Am J Physiol Regul Integr Comp Physiol. 2005;289(2):R380-8.

14. Hernandez TL, Kittelson JM, Law CK, Ketch LL, Stob NR, Lindstrom RC, Scherzinger A, Stamm ER, Eckel RH. Fat redistribution following suction lipectomy: defense of body fat and patterns of restoration. Obesity (Silver Spring). 2011;19(7):1388-95.

15. Benatti F, Solis M, Artioli G, Montag E, Painelli V, Saito F, Baptista L, Costa LA, Neves R, Seelaender M, Ferriolli E, Pfrimer K, Lima F, Roschel H, Gualano B, Lancha A Jr. Liposuction induces a compensatory increase of visceral fat which is effectively counteracted by physical activity: a randomized trial. J Clin Endocrinol Metab. 2012;97(7):2388-95.

16. Swanson E. Photographic measurements in 301 cases of liposuction and abdominoplasty reveal fat reduction without redistribution. Plast Reconstr Surg. 2012;130(2):311e-22e

17. Yazigi Solis M, Artioli GG, Montag E, de SallesPainelli V, Saito FL, Lima FR, Roschel H, Gualano B, Lancha Junior AH, Benatti FB. The liposuctioninduced effects on adiponectin and selected cytokines are not affected by exercise training in women. Int J Endocrinol. 2014;2014:315382.

18. Olney JW. Brain lesions, obesity and other disturbances in mice treated with monosodium glutamate. Science. 1969;164:719-21.

19. Olney JW. Glutamate-induced retinal degeneration in neo-natal mice. Electron microscopy of the acutely evolving lesion. J Neuropath Exp Neurol. 1969;28:455-74

20. Olney JW. Glutamate-induced retinal degeneration in neo-natal mice. Electron microscopy of the acutely evolving lesion. J Neuropath Exp Neurol. 1969;28:455-74.

21. Lemkey-Johnston N, Reynolds WA. Nature and extent of brain lesions in mice related to ingestion of monosodium glutamate: A light and electron microscope study. J Neuropath exp Neurol. 1974;33:74-97.

22. Dolnikoff MS, Kater CE, Egami M, de Andrade IS, Marmo MR. Neonatal treatment with monosodium glutamate increases plasma corticosterone in the rat. Neuroendocrinology. 1988;48(6):645-9.

23. Nemeroff $C B$, Grant LD, Bissette G, Ervin GN, Harrell LE, Prange AJ Jr. Growth, endocrinological and behavioral deficits after monosodium Lglutamate in the neonatal rat: possible involvement of arcuate dopamine neuron damage. Psychoneuroendocrinology. 1977;2(2):179-96.

24. Nenoff $P$, Remke $H$, Müller F, Arndt T, Mothes T. In vivo assessment of insulin binding in different organs of growing and adult glutamate-induced obese rats. Exp Clin Endocrinol. 1993;101(4):215-21.

25. Kizer JS, Nemeroff CB, Youngblood WW. Neurotoxic amino acids and structurally related analogs. Pharmacol Rev. 1977;29(4):301-18.

26. Remke H, Wilsdorf A, Müller F. Development of hypothalamic obesity in growing rats. Exp Pathol. 1988;33(4):223-32.

27. Pizzi WJ, Barnhart JE. Effects of monosodium glutamate on somatic development obesity in KK mice. Pharmacol Biochem Behav. 1976;5:551-7.

28. Olney JW, Ho OL. Brain damage in infant mice following oral intake of glutamate, aspartate or cysteine. Nature (Lond). 1970;227:609-10.

29. Abraham R, Doughtery W, Goldberg L, Coulston F. The response of the hypothalamus to high doses of monosodium glutamate in mice and monkeys. Cytochemistry and ultra- structural study of lysosomal changes. Expl Molec Path. 1971;15:43-60.

30. Burde RM, Acute BS, Kayes J. Monosodium glutamate: Acute effect of oral and subcutaneous administration on the arcuate nucleus of the hypothalamus in mice and rats. Nature, (Lond.). 1971;233:58-60.

31. Everly JL. Light microscopic examination of MSG-induced lesions in brain of fetal and neonatal rats. Anat Rec. 1971;169:312.

32. Murakami U, Inouye M. Brain lesions in the mouse fetus ojed by maternal administration of monosodium glutamate. Congenital Anomalies. 1971;11:171-7.

33. Olney JW, Sharpe LG, Feigin RD. Glutamate-induced brain damage in infant primates. J Neuropath Exp Neurol. 1972;31:464-88.

34. Shimizu K, Mizutani A, Inouye M. Electron microscopic studies on the hypothalamic lesions in the mouse fetus caused by monosodium glutamate. Teratology. 1973;8:105.

35. Shi H, Strader AD, Woods SC, Seeley RJ. Sexually dimorphic responses to fat loss after caloric restrictionor surgical lipectomy. Am J Physiol Endocrinol Metab. 2007;293:E316-26.

36. Vague J. La differe'nciation sexuelle, facteur determinant des formes de l'obe'site. Presse Med. 1947;55:339-40,

37. Bouchard C, Despre's J-P, Maurie'ge PO. Genetic and nongenetic determinants of regional fat distribution. Endocr Rev. 1993;14:72-93.

38. Fujioka S, Matsuzawa Y, Tokunaga K, Tarui S. Contribution of intraabdominal fat accumulation to the impairment of glucoseand lipid metabolism in human obesity. Metabolism. 1987;36:54-9.

39. Despre's J-P, Nadeau A, Tremblay A, Ferland M, Moorjani S, Lupien PJ, The'riault G, Pinault S, Bouchard C. Role of deep abdominal fat in the association between regional adipose tissue distribution and glucose tolerance in obese women. Diabetes. 1989:38:304-9.

40. Pouliot M-C, Despre's J-P, Nadeau A, Moorjani S, Prud'Homme D, Lupien PJ, Tremblay A, Bouchard C. Visceral obesity in men. Associations with glucose tolerance, plasma insulin and lipoprotein levels. Diabetes. 1992;41:826-34.

41. Jensen MD. Role of body fat distribution and the metabolic complications ofobesity. J Clin Endocrinol Metab. 2008;93(11 Suppl 1):S57-63.

42. Morris MJ, Tortelli CF, Filippis A, Proietto J. Reduced BAT function as a mechanism for obesity in the hypophagic, neuropeptide $Y$ deficient monosodium glutamate-treated rat. Regul Pept. 1998;75-76:441-7.

43. Tokuyama K, Himms-Hagen J. Brown adipose tissue thermogenesis, torpor, and obesity of glutamate-treated mice. Am J Phys. 1986;251(4 Pt 1):E407-15.

44. Lönnqvist F, Thorne A, Large V, Arner P. Sex differences in visceral fat lipolysis and metabolic complications of obesity. Arterioscler Thromb Vasc Biol. 1997;17:1472-80.

45. Trayhurn P, Beattie JH. Physiological role of adipose tissue: white adipose tissue as an endocrine and secretory organ. Proc Nutr Soc. 2001;60(3):329-39.

46. Sell H, Dietze-Schroeder D, Eckel J. The adipocyte-myocyte axis in insulin resistance. Trends Endocrinol Metab. 2006;17(10):416-22.

47. Sell H, Divoux A, Poitou C, Basdevant A, Bouillot JL, Bedossa P, Tordjman J, Eckel J, Clément K. Chemerin correlates with markers for fatty liver in morbidly obese patients and strongly decreases after weight loss induced by bariatric surgery. J Clin Endocrinol Metab. 2010;95(6):2892-6.

48. DeFronzo RA, Tripathy D. Skeletal muscle insulin resistance is the primary defect in type 2 diabetes. Diabetes Care Suppl. 2009;2:S157-63.

49. Pedersen BK. The diseasome of physical inactivity--and the role of myokines in muscle--fat cross talk. J Physiol. 2009:587(Pt 23):5559-68.

50. Pedersen BK. Exercise-induced myokines and their role in chronic diseases. Brain Behav Immun. 2011;25(5):811-6.

51. Pedersen BK, Febbraio MA. Muscles, exercise and obesity: skeletal muscle as a secretory organ. Nat Rev Endocrinol. 2012;8(8):457-65.

52. Raschke S, Eckel J. Adipo-myokines: two sides of the same coin-mediators of inflammation and mediators of exercise. Mediat Inflamm. 2013;2013:16. Article ID 320724

53. Roca-Rivada A, Castelao C, Senin LL, Landrove MO, Baltar J, Crujeiras AB, et al. FNDC5/risin is not only a myokine but also an adipokine. PLoS One. 2013;8:e60563.

54. Macho L, Ficková M, Jezová, Zórad S. Late effects of postnatal administration of monosodium glutamate on insulin action in adult rats. Physiol Res. 2000;49(Suppl 1):S79-85.

55. Tofovic SP, Zhang X, Jacson EK, Dacic S, Petrusevska G. 2-Methoxyestradiol mediates the protective effects of estradiol in monocritaline-indiced pulmonary hypertension. Vasc Pharmacol. 2006:45:358-67.

56. Wegorzewska IN, Walters K, Weiser MJ, et al. Postovariectomy weight gain in female rats is reversed by estrogen receptor alpha agonist, propylpyrazoletriol. Am J Obstet Gynecol. 2008;199(1):67. 
57. Naaz A, Zak Causroczymski M, Heine $P$, et al. Effect of ovariectomy on adipose tissue of mice in the absence of estrogen receptor alpha (ER alpha): a potencial role for estrogen receptor beta (ER beta). Horm Metab Res, v. 2003;34:758-63.

58. Heine PA, Taylor JA, Iwamoto GA, et al. Increased adipose tissue in male and female estrogen receptor-alpha knockout mice. Proc Nati Acad Sci USA. 2000;97(23):12729-34.

59. CCM N, Marmo MR, Egami M, Ribeiro EB, Andrade IS, Dolnikoff MS. Effect of monosodium glutamate treatment during neonatal development on lipogenesis rate and lipoprotein lipase activity in adult rats. Biochem Int. 1991;24(5):927-35.

60. Miśkowiak B, Kesa B, Limanowski A, Partyka M, Filipiak B. Long-term effect of neonatal monosodium glutamate (MSG) treatment on reproductive system of the female rat. Folia Morphol (Warsz). 1999;58(2):105-13.

61. Castrogiovanni D, Gaillard RC, Giovambattista A, Spinedi E. Neuroendocrine, metabolic, and immune functions during the acute phase response of inflammatorystress in monosodium L-glutamate-damaged, hyperadipose male rat. Neuroendocrinology. 2008;88(3):227-34.

62. Kumagai $S$, Holmäng $A$, Björntorp $P$. The effects of estrogen and progesterone on insulin sensitivity in female rats. Acta Physiol Scand. 1993; 149(1):91-7.

63. Louet JF, LeMay C, Mauvais-Jarvis F. Antidiabetic actions of estrogen: insight from human and genetic mouse models. Curr Atheroscler Rep. 2004;6(3): 180-5.

64. Bryzgalova G, Lundholm L, Portwood N, Gustafsson JA, Khan A, Efendic S, Dahlman-Wright K. Mechanisms of antidiabetogenic and body weightlowering effects of estrogen in high-fat diet-fed mice. Am J Physiol Endocrinol Metab. 2008;295(4):E904-12.

65. Curi CMN, Marmo MR, Egami M, Ribeiro EB, Andrade IS, Dolnikoff MS. Effect of monosodium glutamate treatment during neonatal development on lipogenesis rate and lipoprotein lipase activity in adult rats. Biochem Int. 1991:24(5):927-35

66. Shen M, Kumar SP, Shi H. Estradiol regulates insulin signaling andinflammation in adipose tissue. Horm Mol Biol Clin Investig. 2014;17(2): 99-107.

67. Freedland ES. Role of a critical visceral adipose tissue threshold (CVATT) in metabolic syndrome: implications for controlling dietary carbohydrates: a review. Nutr Metab (Lond). 2004;1(1):12.

68. Spaanderman DCE, Nixon M, Buurstede JC, Sips HC, Schilperoort M, Kuipers EN, Backer EA, Kooijman S, Rensen PCN, Homer NZM, Walker BR, Meijer OC, Kroon J. Androgens modulate glucocorticoid receptor activity in adipose tissue and liver. J Endocrinol. 2018. Pii: JOE-18-0503.R1. https://doi.org/10. 1530/JOE-18-0503.

69. Ochiogu IS, Ogwu D, Uchendu CN, Okoye ON, Ihedioha Jl, Mbegbu EC. Effects of monosodium L-glutamate administration on serum levels of reproductive hormones and cholesterol, epididymal sperm reserves and testicular histomorphology of male albino rats. Acta Vet Hung. 2015;63(1): 125-39

70. Rebuffé-Scrive M, Lundholm K, Björntorp P. Glucocorticoid hormone binding to human adipose tissue. Eur J Clin Investig. 1985;15:267-71.

71. Björntorp P. Endocrine abnormalities in obesity. Diabetes Rev. 1997:5:52-68.

72. Wajchenberg BL, Bosco A, Marone MM, Levin S, Rocha M, Lerario AC, Nery M, Goldman J, Liberman B. Estimation of body fat and lean tissue distribution by dual energy $x$-ray absorptiometry and abdominal body fat evaluation by computed tomography in Cushing's disease. J Clin Endocrinol Metab. 1995;80:2791-4

73. Wajchenberg BL, Liberman B, Giannella Neto B, Morozimato MY, Semer M, Bracco LO, Salgado LR, Knoepfelmacher M, Borges MHS, Pinto ACAR, Kater C, Lengyel AMJ. Growth hormone axis in Cushing's syndrome. Horm Res. 1996:45:99-107.

74. Ribeiro EB, do Nascimento CM, Andrade IS, Hirata AE, Dolnikoff MS. Hormonal and metabolic adaptations to fasting in monosodium glutamateobese rats. J Comp Physiol B. 1997;167(6):430-7.

75. Macho L, Jezova D, Zorad S, Fickova M. Postnatal monosodium glutamate treatment results in attenuation of corticosterone metabolic rate in adult rats. Endocr Regul. 1999;33(2):61-7.

76. Guimarães ED, de Caires Júnior LC, Musso CM, Macedo de Almeida M Gonçalves CF, Pettersen KG, Paes ST, González Garcia RM, de Freitas Mathias PC, Torrezan R, Mourao-Júnior CA, Andreazzi AE. Altered behavior of adult obese rats by monosodium $\mathrm{L}$-glutamate neonatal treatment is related to hypercorticosteronemia and activation of hypothalamic ERK1 and ERK2. Nutr Neurosci. 2017;20(3):153-60.

77. Glass AR. Endocrine aspects of obesity. Med Clin North Am. 1989;73:139-60.

78. Brummer RJM, Lónn L, Kvist H, Grangård U, Bengtsson B-A, Sjöström L. Adipose tissue and muscle volume determination by computed tomography in acromegaly before and 1 year after adenomectomy. Eur J Clin Investig. 1993;23:199-205.

79. DeFelice SL. The nutraceutical revolution: its impact on food industry R\&D. Trends Food Sci Technol. 1995:6:59-61.

80. Kalra EK. Nutraceutical-definition and introduction. AAPS PharmSciTech. 2003;5:E25.

81. Scicchitanoa P, Camelib M, Maielloc M, Modestid PA, Muiesane ML, Novof S, Palmieroc P, Sabag PS, Pedrinellih R, Cicconea MM. Nutraceuticals and dyslipidaemia: beyond the common therapeutics. J Funct Foods. 2014;6:1132.

82. Ton AMM, Arpini CM, Campagnaro BP, Pereira TMC, Vasquez EC. Alzheimer's disease: A brief update on the influence of gut microbiota and the impact of functional food. J Food Microbiol. 2018;2(1):11-5.

83. Chen WP, Ho BY, Lee $C L$, et al. Red mold rice prevents the development of obesity, dyslipidemia and hyperinsulinemia induced by high-fat diet. Int J Obes. 2008;32:1694-704

84. Milenkovic D, Deval C, Gouranton E, Landrier JF, Scalbert A, Morand C, Mazur A. Modulation of miRNA expression by dietary polyphenols in apoE deficient mice: A new mechanism of the action of polyphenols. PLoS One. 2012;7:e29837

85. Park HJ, Yang JY, Ambati S, Della-Fera MA, Hausman DB, Rayalam S, Baile CA. Combined effects ofgenistein, quercetin, and resveratrol in human and 3T3-L1 adipocytes. J Med Food. 2008;11:773-83.
Ready to submit your research? Choose BMC and benefit from:

- fast, convenient online submission

- thorough peer review by experienced researchers in your field

- rapid publication on acceptance

- support for research data, including large and complex data types

- gold Open Access which fosters wider collaboration and increased citations

- maximum visibility for your research: over $100 \mathrm{M}$ website views per year

At $\mathrm{BMC}$, research is always in progress.

Learn more biomedcentral.com/submissions 